\title{
As mutações da escola média na Argentina no marco da reconfiguração de um mundo globalizado'
}

\author{
Guillermina Tiramonti *
}

Resumo: Neste texto, a autora analisa a reconfiguração dos sistemas educacionais e os processos que os atravessam no marco das transformaçôes sociais e culturais dos últimos anos. Introduz a idéia de fragmentação do sistema, estabelecendo diferenças entre este novo conceito e o tradicional conceito de segmentação educacional, ao mesmo tempo que fundamenta teoricamente essa conceitualização. Aborda, além disso, as mudanças na trama institucional, geradas pela modernidade (família, Estado, escola) e seu impacto na constituição das subjetividades, por meio da caracterização das assincronias na individualização de alunos pertencentes a diferentes setores socioculturais. Por fim, identifica os mandatos que, requeridos pelo presente, recaem sobre a escola em termos de inclusão, contenção e atenção.

Palavras-chave: fragmentação educacional; individualização; novos mandatos escolares.

\section{The changes in Argentinian high school at the landmark of reorganizing a globalized world}

Abstract: In this text, the author analyzes the reorganization of educational systems and the processes that have affected it along the important social and cultural changes of the latest years. She also introduces the idea of a fragmentation of the educational system, establishing differences between this new concept and the traditional concept of educational breakup, and explaining this conceptualization with theoretical bases. She also approaches the changes in institutional structures, generated by modernity (family, the State and schools) as well as their impact on the constitution of subjectivities through the characterization of asynchrony in the individualization of students from different socio-cultural backgrounds. The author finally identifies prescriptions which are present-time demands and must be faced by schools in terms of inclusion, restraint and fulfillment.

Key words: educative fragmentation; individualization; new scholar mandates.

* Mestre em Educação e Sociedade pela Facultad Latinoamericana de Ciências Sociales (FLACSO). Professora titular da cátedra Políticas Educativas, Universidad Nacional de la Plata (UNLP), Argentina. Coordenadora do Mestrado em Ciências Sociais, com orientação em Educação, da Facultad Latinoamericana de Ciencias Sociales (Flacso), Argentina. Diretora da Facultad Latinoamericana de Ciencias Sociales. Últimas publicações: La trama de la desigualdad educativa. Mutaciones recientes em la escuela media. Buenos Aires: Manantial, 2004. La educación de las elites. Aspiraciones, estrategias y oportunidades. Buenos Aires: Paidós. (Organizado em colaboração com Ziegler).tiramonti@flacso.org.ar.

।. Tradução: Rosiver Pavan (rosiver.pavan@gmail.com). Revisão técnica: Nora Rut Krawczyk 
Nas sociedades modernas, a escola sustentou um duplo mandato social que expressa a tensão que atravessam as sociedades capitalistas modernas entre a destruição permanente das hierarquias e a construção de novos mecanismos de seleção e diferenciação social. Esta tensão, processada de formas muito diferentes pelas sociedades, na Argentina, adquiriu características específicas devido ao papel central que desempenharam as credenciais educativas na estratégia de ascensão social das classes médias nacionais.

Por um lado, a luta contra os obstáculos educativos gerou um sistema educacional no qual não existem mecanismos formalmente estabelecidos para a seleção da população e sua inclusão em circuitos diferenciados. De forma que, no interior de um sistema que se apresenta como igual para o conjunto da população, desenvolveu-se, digamos, até os finais dos anos 1970, uma luta desregrada de todos contra todos, na qual são postos em movimento os recursos com que cada um conta para sobreviver no sistema e obter a credencial desejada. No contexto de uma Argentina medianamente integrada e, além disso, de espaços escolares socialmente plurais, essa metodologia possibilitou a ascensão de alguns e a legitimação da exclusão de outros.

Ao longo do século XX, à medida que se incorporavam novos atores sociais na disputa pela educação, as metodologias de processamento complexificaramse sem abandonar a característica de luta desregulada, na qual as decisões individuais são as que definem a ação. A construção de circuitos diferenciados dentro do sistema, como pode ser caracterizado o segmento das escolas técnicas surgidas durante a primeira presidência de Perón, ou o avanço, nos anos 1960, do paulatino crescimento de um circuito privado que começou a abrigar grupos de classe média alta que abandonavam a escola pública à medida que esta se tornava mais inclusiva, somaram-se à tradicional diferenciação por inclusão/exclusão, gerando mecanismos agregados e justapostos de seleção e diferenciação social.

Por meio dessa matizada estrutura de instituições com diferentes graus de prestígio social e pedagógico e trajetórias individuais de maior ou menor êxito, o sistema processou a tensão entre igualdade e seleção, mantendo vivas as expectativas sociais e individuais em relação ao potencial igualador da escola. $\mathrm{Na}$ recriação permanente da possibilidade igualadora da escola desempenhou um papel central o apelo ao Estado Nacional e a sua capacidade de intervir beneficamente no sistema.

O conceito de segmentação educacional pelo qual se vem caracterizando, desde os anos 1980, a desigualdade do sistema educacional nacional a partir das investigações de Braslavsky ${ }^{2}$ inscreve-se nesse marco de expectativas favorá-

2. Cavarozzi, Marcelo (1999). El modelo latinoamericano: su crisis y la génesis de un espacio continental. In: Garretón, Manuel: América Latina: un espacio cultural en el mundo globalizado. Convenio Andrés Bello. Bogota. 
veis relativas à potencialidade igualadora da educação. Supõe-se a existência de um campo integrado simbolicamente pelo Estado, no qual se reconhecem diferenças entre grupos de instituiçōes (denominados segmentos) que podem se situar em uma escala graduada de maior ou menor qualidade educacional. $\mathrm{O}$ Estado é ao mesmo tempo aquele que dá os sentidos universais e o que tem em suas mãos a possibilidade de homogeneizar o sistema por meio de uma política educacional que rompa o cerco social que efetuam os setores dominantes sobre os saberes socialmente relevantes.

A partir da reestruturação que a sociedade sofreu nos últimos 30 anos da ruptura da matriz estadocêntrica da sociedade e da experiência da crise de 2001, é necessário repor a discussão acerca da desigualdade. Pensar a nova configuração da desigualdade educacional exige recuperar um olhar abrangente da totalidade do sistema sempre que a desigualdade tenha um caráter relacional e decorra de vinculações particulares e relações sociais que comprometem o conjunto da sociedade e não apenas aos que pertencem a determinado estrato. Durante os anos 1990, o tratamento da desigualdade reduziu-se ao estudo dos pobres e à identificação de suas falências. A pobreza foi pensada como um atributo de determinados indivíduos ou grupos e a desigualdade como carência absoluta ou comparativa em relação ao acesso a bens ou serviços. As políticas compensatórias foram e são pensadas como instrumentos de reposição social dessas carências.

Do nosso ponto de vista, a configuração desigual das oportunidades educacionais requer a análise das assimetrias nos processos que perpassam o conjunto do sistema e das linhas de quebra e diferenciação que se registram tanto nas características institucionais como na conformação das subjetividades.

\section{A configuração fragmentada do sistema}

Há uma abundante bibliografia de ciências sociais que faz referência à condição fragmentada da sociedade. Diferentemente do segmento, que se constitui como um espaço diferenciado em um campo integrado, a fragmentação remete a um campo explodido caracterizado por rupturas, descontinuidades e impossibilidade de passagem de um fragmento a outro. A fragmentação nomeia a perda da unidade, a ausência de referências comuns e uma dinâmica de multiplicação fragmentada que afasta toda possibilidade de recuperação da unidade.

já não cremos no mito da existência de fragmentos que, como pedaços de uma estátua antiga, esperam que a última peça faltante seja descoberta para, então, serem colados criando uma unidade exatamente igual à unidade original (Deleuze; Guatari, 1998, apud Bauman, 2000). 
Nossas sociedades estão em processo de fragmentação, de separação permanente, de construção de homogeneidades que se separam e se distinguem de outros corpos homogêneos que conformam entre si um heterogêneo agregado de instituiçôes, agentes, grupos e indivíduos.

A fragmentação social tem continuidades claras no campo educacional e é este o conceito que, cremos, melhor explica a configuração atual do sistema educacional. $\mathrm{O}$ fragmento é um espaço auto-referido no interior do qual se podem distinguir continuidades e diferenças; as primeiras, marcando os limites ou as fronteiras do fragmento e as outras, dando conta da heterogeneidade desses espaços. Assim, o fragmento atua como uma fronteira de referência, mas não se constitui no todo integrado e coordenado, nem sequer em um campo no qual se podem reconhecer posicionamentos de atores e instituiçóes, tratando-se antes de agregados institucionais que têm referências normativas e culturais comuns.

\section{Precisões conceituais}

Há dois conceitos que contribuem para a construção da idéia de fragmentação. O primeiro desses conceitos é o de cerco social forjado por Weber para explicar os processos pelos quais as comunidades excluem, limitam ou condicionam o acesso a determinados recursos ao restante dos membros da sociedade. Esses processos de cerco podem originar-se nas tradiçōes, no afeto, na identidade, na religião ou em motivações nitidamente racionais.

Neste último caso, o processo de cerco está associado à tendência das comunidades de ampliar ao máximo suas recompensas, para o que "limitam" o acesso a recursos e a oportunidades a um número reduzido de pessoas. Os atributos de idade, de religião, de etnia, de sexo, etc. podem ser utilizados para limitar o acesso. Trata-se de uma forma de segregação que afeta a distribuição de "certos bens sociais" ou impede um acesso aberto a recursos "socialmente valorizados".

Esta noção de cerco social e de tendência à monopolização dos bens sociais estava já presente no texto de Braslavsky (1985), La discriminación educativa, no qual se explica que a segmentação do sistema educacional decorria de uma distribuição segregada do bem educacional que impedia que os setores mais desfavorecidos tivessem acesso aos saberes socialmente valorizados, os quais eram, portanto, monopolizados pelos setores dominantes.

Nesse caso, a idéia de cerco estava associada à de monopolização de saberes e, por sua vez, os processos de ensino-aprendizagem eram reduzidos a uma ação comunicativa de transmissão de conhecimentos. As diferenças nas aprendizagens resultavam de práticas monopolizadoras que limitavam ou impediam 
o acesso ao conhecimento socialmente valorizado a certos setores sociais.

Essa idéia supunha também certa segregação e separação dos públicos escolares, pois em algumas escolas, freqüentadas pelos setores dominantes, a transmissão escolar dava acesso a saberes relevantes, e em outras escolas, freqüentadas pelos setores médios e baixos da população, a prática escolar impedia esse acesso ou fazia circular saberes degradados ou socialmente irrelevantes.

Os setores dominantes, como os chamava Braslavsky, ou as elites, como as denomina Svampa (2005), historicamente habitaram espaços segregados onde desenvolveram uma sociabilidade de tipo comunitário, destinada à conservação de posiçôes e à reprodução social dentro de um espaço determinado. Tais práticas de segregação constroem diferentes círculos de pertencimento definidos pela linhagem social, pelas práticas desportivas, pelos modos de vida, etc. A escolha das instituições escolares esteve desde sempre, para esses setores, associada a essa prática de segregação e de construção de espaços socialmente fechados que garantiam homogeneidade social e cultural no âmbito institucional.

Nos últimos anos, esse modo segregado de a sociedade conviver difundiu-se entre outros estratos sociais. Assistimos à construção de bairros fechados tanto para as elites como para amplo espectro das classes médias. Vive-se segregadamente, e a vida social transcorre em espaços controlados onde se limita o acesso de outros não pertencentes à comunidade. $\mathrm{O}$ mapa completa-se com as tendências de segregação dos próprios excluídos, que não só são deslocados às periferias de onde desenvolvem estratégias de irrupção no espaço da cidade como, por sua vez, desenvolvem estratégias de cerco social como resposta ou reação a sua condição de estranhos (Parem, 1864, p.70). O conceito de fragmentação social tenta dar conta de uma configuração da sociedade que decorre dos modos segregados das práticas sociais.

Pois bem, quando falamos de fragmentação estamos fazendo alusão a um modo de segregação que constrói uma específica distância social entre aqueles que habitam os diferentes fragmentos. De Durkheim adiante, a sociologia analisou os modos de articulação, de intercâmbios e de contatos que se produzem entre aqueles que partilham um determinado espaço social. Para esse autor, a insuficiência dos contatos entre os grupos que compóem a sociedade está na base dos processos de desorganização social. A partir dessa perspectiva, a coesão e a solidariedade social não podem se desenvolver se a distância social entre os diferentes grupos é profunda. Estabelece-se assim uma associação entre distância social e violência.

Constrói-se esta conexão a partir da idéia de que a distância gera fronteiras morais. A moral delineia, para esse autor, os limites entre a inclusão e a exclusão; legitima a sanção legal para quem está dentro do marco normativo e o 
exercício da violência para aqueles que estão fora da comunidade e não compartilham as regras estabelecidas. As justificativas que os governos impunham em relação à repressão ao terrorismo ilustram a legitimação do exercício da violência sobre os que estão fora do limite da moral.

Simmel utiliza o termo "distância social" para distinguir o intercâmbio entre as relações primárias - sociedades comunitárias - e as relações secundárias - institucionais ou sociais. Park (1924, apud Bottello; Lara Carmona, 2004³) retoma essa idéia e observa que o conceito de distância social permite apreciar o grau de entendimento e intimidade que caracterizam as relaçôes pessoais ou sociais.

Trata-se de um conceito que contrasta com o de diferenciação estrutural. A distância social está relacionada com o cultural e a moral, faz alusão aos laços de entendimento e intimidade entre os grupos que compóem a sociedade, enquanto a diferenciação estrutural faz referência a condições objetivas - econômicas e políticas - da desigualdade. Claro que as diferenças objetivas desempenham um papel central na definição da qualidade do laço social e, portanto, da "distância entre os diferentes grupos". No entanto, o que queremos sublinhar é que há elementos culturais que atuam na construção da distância social que têm uma qualidade diferente quando falamos de segmentação e quando falamos de fragmentação.

Como já afirmamos, a segmentação faz referência a um todo integrado no qual as distâncias entre os grupos podem ser medidas em termos de graus, enquanto a distância que se nomeia com a noção de "fragmentação" é diferente porque faz alusão à existência de mundos culturais distantes, cujos conteúdos só admitem o contraste, mas não a comparação e, muito menos, seu ordenamento em uma escala hierárquica.

Usamos a idéia de fragmentação para nomear uma distância que se expressa em termos de estranhamento cultural e que demarca fronteiras do pertencimento das quais os outros estão fora, pertencem a outros mundos. Quando afirmamos que o campo educacional está fragmentado, fazemos referência a distâncias que não podem ser medidas em termos de maior ou menor (seja tratar-se de conhecimentos, capital cultural ou habilidades intelectuais), mas que se distinguem por pertencimentos a mundos culturais que diferem entre si, em virtude dos valores, das expectativas e dos modos de vida que os organizam.

Temos advertido em trabalhos anteriores que não se trata de mundos homogêneos e orgânicos; pelo contrário, podem ser identificadas incongruências

3. Park. The concept of social distance: as applied to the study of racial relations. Journal of Applied Sociology, n.8, 1924. 
e heterogeneidades, seja entre as diferentes instituições que compõem um mesmo fragmento, como na proposta escolar e os grupos comunitários aos quais se articulam. Sem dúvida, essas diferenças que, por outro lado, estão na base de uma dinâmica de permanente fragmentação, estabelecem diálogo com um "pacote cultural" que serve de referente comum ${ }^{4}$.

Definitivamente, o termo fragmentação é tributário do conceito de cerco social weberiano, porque dá conta de uma forma específica de segregação social na qual a tendência é a de gerar espaços socioculturalmente homogêneos, e essa configuração particular, por sua vez, gera uma distância social entre os grupos que se caracteriza pelo alheamento.

Deveríamos acrescentar que, diferentemente das sociedades estamentais caracterizadas pela estabilidade dos pertencimentos e pela sua legitimação a partir de uma cosmovisão que inclui o todo, a configuração fragmentada é mutante; há uma dinâmica de permanente fragmentação que impede recuperar o todo e que, sobretudo, é um fenômeno próprio de um mundo não estável, mutante e ameaçador das posiçõos adquiridas.

\section{Processos de individualização}

Há consenso entre os cientistas sociais quando sublinham que as modificações estruturais que a sociedade contemporânea atravessa estão alterando as relações entre indivíduo e sociedade.

A caracterização desse vínculo foi um tema central da sociologia. Segundo o esquema tradicional, há uma separação profunda entre indivíduo e sociedade e, esta última, que existe por fora e por cima dos indivíduos, molda a conduta destes por meio de um processo de socialização pelo qual se constituem as subjetividades. De forma que a subjetividade não é outra coisa que a incorporação do social que define os costumes, as aspirações, os valores e os interesses. Os indivíduos são, nesta concepção, uma feitura da sociedade.

As teorias mais modernas da socialização explicam que não se trata só de internalização de valores, mas que, além disso, o processo de socialização inclui a construção social do corpo. De modo que os gestos, os movimentos e as posturas não são naturais, mas marcas que expressam determinadas trajetórias e posicionamentos sociais. Bourdieu cunhou o conceito de habitus para expli-

4. Tripathi realizou estudos na Índia sobre o sistema de castas e a forma pela qual este se expressa nas relações interpessoais e na construção de estereótipos sociais. Em seu trabalho, sustenta que esse modo de organização social paradoxalmente permite um lugar a cada grupo do sistema, dando uma perspectiva de unidade e sentido aos membros de cada casta, que minimiza o conflito (em Arteaga Botello y Lara Carmona: Tripathi, B. D. 1967. On minimizing social distance existing between the upper castes and harijans. Interdiscipline, v. 4, n. 4, p. 316-32I). 
car essa aprendizagem do corpo. No mesmo sentido, Foucault fala das tecnologias de governo baseadas em determinados saberes destinados a gerar sujeitos em conformidade com o projeto dominante.

Elias (1990) avança ao libertar os conceitos de indivíduo e sociedade dos significados anteriores, colocando-os em uma relação de reciprocidade segundo a qual a sociedade dá forma à individualidade de seus membros, e os indivíduos participam de sua construção por meio dos atos de sua vida nos quais põem em prática estratégias possíveis e viáveis dentro das interdependências do tecido social. Segundo essa postura, a sociedade moderna exerce uma incessante ação individualizadora que se modifica permanentemente por meio de uma negociação que supõe uma constante redefinição de laços entre indivíduo e sociedade.

Para uma série de autores, a etapa que estamos atravessando se caracteriza por uma modificação profunda na relação entre indivíduo e sociedade em favor da primazia dos sujeitos sobre as determinações sociais. De acordo com Beck (2000), a sociedade industrial como sistema, ou seja, a dinâmica da economia, da política e da ciência provocou a decomposição da sociedade industrial como trama de experiências, desancorando as pessoas das seguranças e das formas de vida estandardizadas. Por sua vez, Bauman (2000) afirma que a modernidade "desenraizou-se" prematuramente para poder "reenraizar-se", de forma que, uma vez que o rígido marco dos estamentos sociais foi quebrado, a tarefa para os indivíduos foi aculturar-se nos novos marcos regulatórios da ação. Assim, os estamentos em tantos lugares de pertencimento herdados foram recolocados pelas classes como espaços de pertencimento fabricados. Diferentemente desse processo de individualização na atual etapa do capitalismo que Bauman chama líquida, não existem canteiros onde "reenraizemos"; o que há é uma variedade de "jogos de cadeira" nos quais ditas cadeiras têm diversos tamanhos e estilos, cuja quantidade e localização variam, obrigando homens e mulheres a estar em permanente movimento, sem prometer-lhes "completude" alguma. Não existe perspectiva de reenraizamento ao final do caminho tomado pelos indivíduos já cronicamente desenraizados.

De forma que este momento da modernidade está atravessado por um processo de desinstitucionalização que se expressa na insuficiência das instituiçôes organizadas durante a era industrial para regular e determinar os comportamentos individuais ou, o que é o mesmo, para constituir-se como marco existencial que contém e marca as trajetórias individuais.

A articulação Estado, escola e família constituiu o suporte institucional da ordem social moderna que, por sua vez, inventou uma ética, a do trabalho, e uma moral laica que impunha deveres e obrigações tão exigentes como os anteriores dogmas religiosos. O ideal de sacrifício e a fé no progresso é o que susten- 
ta a promessa moderna. É justamente essa estrutura de instituições e justificações que parece estar se modificando.

Escreveu-se muito sobre a decadência do Estado-Nação e, embora não seja nosso interesse recriar aqui essa discussão, é necessário, sem dúvida, mencionar, para o tema que nos interessa, a perda simbólica do Estado como articulador da ordem e provedor de um sentido universal ao conjunto das açóes que se desenvolvem em uma determinada sociedade. A ausência ou a debilidade desse ator é o pano de fundo da configuração fragmentada de nossa sociedade.

Há também uma extensa literatura que analisa as mudanças na instituição familiar, tanto em sua composição como no tipo de laço que articula seus membros. A demografia explica as novas modalidades de união e de dissolução dessas uniões, os tipos emergentes de composição familiar (coabitação, monoparentesco, ajuntamento) e a redefinição das trajetórias matrimoniais (Torrado, 2003).

A emancipação feminina e os processos de individualização provocaram a erosão da estrutura familiar hierárquica da família patriarcal. Há, sem dúvida, uma democratização dos laços e uma mudança nas formas de convivência. $\mathrm{O}$ espaço familiar transformou-se em um ponto de encontro dos projetos individuais de seus membros, diferentemente das conformaçôes tradicionais que articulavam em um único projeto as trajetórias de vida de seus integrantes. $\mathrm{O}$ sexo, a idade e o parentesco definiam os deveres e as opções de vida. As possibilidades individuais estavam fundamentadas por categorias estabelecidas pela natureza e fechadas pela decisão dos homens (Beck, 1999).

Há posições muito diferentes na avaliação dessas mudanças. Para Beck (1999), por exemplo, estamos diante de um processo de ampliação das liberdades individuais, em que o conflito e o compromisso entre geraçôes se processam mediante acordos e negociações. Para outros autores (Laïdi, 20005, apud Tedesco, 2003), estamos diante de uma crise de transmissão intergeracional, pois que a "transmissão efetuada no seio da família já não se apóia na aceitação do princípio da autoridade $[\ldots]$ mas que o único princípio válido é o democrático ou, dito em outras palavras, a revitalização das opiniões" (Tedesco, 2003, p.58).

De acordo com os dados da pesquisa ${ }^{6}$ que deu base a este texto, na representação dos jovens de referência, a família aparece em seus discursos permanentemente e, ao mesmo tempo, como aspiração de realização futura (Montes,

5. LAïDI, Z. La sacre du present. Paris: Flammarion, 2000.

6. Estamos fazendo referência à pesquisa "La nueva configuración de la discriminación educativa" que se desenvolve no marco da área de Educação da Flacso, com financiamento da SECYT e com a direção da autora. A pesquisa trabalha com uma amostra de 14 escolas médias nas quais se incluíram instituições que atendem a diferentes setores socioculturais. 
2004). Segundo esses resultados, a característica familiar que os jovens mais valorizam são os laços de horizontalidade que permitem um diálogo aberto entre gerações. Ao mesmo tempo, seus pais (os jovens de ontem), quando fazem referência a suas famílias de origem, criticam a falta de comunicação entre pais e filhos, a intolerância e a falta de apoio para os projetos individuais. A partir desses discursos, a horizontalidade constitui um avanço satisfatório para todos seus membros. Giddens (2000) fala de relações "puras" para nomear articulações baseadas na comunicação emocional, nas quais as recompensas derivadas das mesmas são a base primordial para sua continuidade.

As tendências à desinstitucionalização estariam também afetando a escola. Segundo Dubet e Martuccelli (1998), a imagem de uma norma escolar que se "espraia" na personalidade dos alunos não é mais aceitável. O que está em crise é o modelo da escola republicana, na qual a conduta dos diversos atores estava fortemente regulada e definida de antemão. Cabem aqui todas as considerações sobre a passagem da sociedade disciplinar, caracterizada por Foucault (1996) como aquela na qual a dominação social se constrói por meio de uma rede de dispositivos. Estes produzem e regulam os costumes, os hábitos e as práticas produtivas, a sociedade do controle (Deleuze, 1991), nos quais o poder se exerce mediante engenharias que organizam diretamente os cérebros por meio dos sistemas de comunicação e das redes de informação.

Ao mesmo tempo em que as instituições perdem a capacidade de regulação, modificam-se os marcos éticos que condicionam a ação. Bauman (1999) sustenta que a estética do consumo governa ali onde antes o fazia a ética do trabalho. A ética do trabalho refere-se a um princípio fundante da estrutura normativa e política da sociedade industrial. Ao associar esforço à dignidade individual e social, permitiu, de um lado, satisfazer a necessidade de mão-de-obra da indústria nascente e, de outro, estabelecer um princípio normativo que regulava a moral pública e privada. Segundo este autor, está claro que não é a ética do trabalho a que estrutura a comunidade atual e os jovens dos setores médios e altos. Para estes, a aspiração não é a vida digna, mas a boa vida que se obtém mediante a otimização das possibilidades de escolha. De fato, o valor do trabalho é hoje um fator de estratificação (Tiramonti, 2004) que diferencia os setores altos e médios - que associam trabalho à vocação e à realização pessoal dos estratos mais baixos da escala social, ainda vinculados aos princípios da ética do trabalho, os quais associam à condição socialmente digna.

$\mathrm{Na}$ mesma linha, Lipovesky (2000) fala de uma sociedade pós-moralista que caracteriza como uma sociedade que repudia a retórica do dever austero, integral, maniqueísta e, ao mesmo tempo, coroa os direitos individuais à autonomia, ao desejo, à felicidade. Trata-se de uma ética que não impõe nenhum sacrifício maior, nenhum "arrancar-se de si mesmo"; não há dever heróico, mas 
reconciliação com a felicidade e a festa, com a virtude ou o interesse, com os imperativos do futuro e a qualidade de vida no presente.

Ter-se-ia que pensar então que os jovens constroem suas vidas com autonomia em relação à rede de instituições nas quais estão inseridos, nas quais transcorre boa parte de sua existência. Que presença têm as famílias e as instituições escolares nos modos pelos quais os jovens exercem sua individualidade? Com que recursos e condições os jovens preparam sua própria vida?

A pesquisa que estamos desenvolvendo lança alguma luz sobre essa problemática, mostrando uma complexidade que se expressa nos novos modos pelos quais família e escola se fazem presentes na construção dos fazedores do futuro. Para a elaboração deste texto, trabalhamos com base em uma série de entrevistas realizadas com jovens pertencentes a setores médios e médios altos da cidade de Buenos Aires e da Grande Buenos Aires. Ficam excluídos de nossa análise os jovens pertencentes aos setores mais baixos da escala social e aqueles que a literatura sociológica nomeia como excluídos ou marginais, que são hoje uma presença quantitativa e qualitativamente significativa na Argentina.

Sem dúvida, apesar de sua importância, nesta etapa da pesquisa privilegiamos um olhar sobre as camadas médias e superiores para capturar a heterogeneidade de situaçóes que têm lugar no interior de um grupo social que foi submetido a mudanças, mas que mantém certa autonomia em relação às exigências de sobrevivência. Em uma etapa anterior da investigação, incluímos os jovens dos setores mais baixos que transitavam também por um processo chamado por Robles (1999) de "individuação", em que o imperativo da construção individual do futuro se transforma em um abandono que se expressa no sintagma "vire-se como puder". Em uma nota a ser introduzida mais adiante incorporamos uma aproximação com esse grupo obtida na pesquisa citada.

De outro lado, no espaço social caracterizado pela desintegração e pela marginalidade, os processos de desinstitucionalização são um dado quase óbvio de uma realidade que foi justamente caracterizada por estar à margem da rede de instituições e intercâmbios da sociedade.

\section{Assimetrias nos processos de individualização de jovens escolarizados}

Em nossas pesquisas de campo, registraram-se diversos indícios de que este processo está reconfigurando claramente as relações entre jovens, família e escola, pertencentes a todo o espectro de posições socioculturais. Sem dúvida, o processo caracteriza-se pela heterogeneidade de manifestações e por certa autonomia dos pertencimentos socioeconômicos. Nesse sentido, é possível afirmar que, exceto para os setores mais baixos do espectro social, que estão submetidos à tirania da necessidade e à ameaça da desintegração, para o restante do espec- 
tro de classes médias e altas são variáveis culturais que explicam as diferentes manifestações da individualização.

Em nosso critério, é na convergência entre culturas familiares, expectativas juvenis e formas de socialização escolar que se constroem diferentes experiências de individualização. Na continuação, trataremos de caracterizar a diversidade de situaçôes que identificamos entre jovens de classes médias e altas da sociedade argentina.

\section{A individualização reproduzida}

Para um grupo de jovens de classe média e alta, a possibilidade de construção de uma vida própria está praticamente neutralizada pelo ambiente familiar e escolar que atua inibindo a aparição de opções que alterem as trajetórias predefinidas. Esses jovens podem pertencer aos grupos das elites tradicionais ou ser filhos de setores médios conservadores. Em ambos os casos, os ambientes escolares escolhidos pelos grupos familiares são instituições confessionais. $\mathrm{O}$ pertencimento aos grupos de elite ou de classes médias marca algumas diferenças no interior desse grupo.

Os primeiros provêm de famílias perpassadas por um verdadeiro pavor da desconfiguração da ordem social que até agora permitiu a reprodução da situação de privilégio. Há estratégias explícitas e conscientes destinadas a impedir opções alternativas. Um traço na vida cotidiana dos jovens pertencentes a esse setor é a regulação de suas atividades em marcos institucionais fortes ${ }^{7}$. As escolas que freqüentam organizam-se hierarquicamente e mantêm um rígido controle disciplinar que sustenta sua eficácia nos termos da sanção. O controle disciplinar é o eixo estruturante do conjunto da atividade institucional; inclusive a tarefa pedagógica está sujeita a essa exigência de reprodução da ordem. A

7. No outro extremo da escala social, a vida dos jovens transcorre em espaços públicos ou privados pouco institucionalizados (o bairro, a rua, a casa dos amigos, o baile). A escola, como já dissemos anteriormente, tem escassa capacidade de sustentar e impor um marco normativo diferente daquele que impera no meio. Nesse caso, como no anterior, a escola é um espaço análogo ao do meio social, porém esse meio está marcado pela anomia. Nesse grupo há uma reivindicação de reposição das instituições e dos marcos regulatórios para calçar a vida dos filhos. Trata-se de uma busca desesperada de espaços de enraizamento que atenuem a angústia de um processo de individualização compulsivo, sem recursos nem rede de contenção social. É uma reivindicação "civilizatória" para a escola, uma demanda de incorporação aos códigos dos incluídos. Pede-se um guia para a ação com a qual se possa construir uma trajetória de inclusão. É uma interpelação para que a escola se constitua uma instância de neutralização dos efeitos de "desfiliação" com a qual Castel ( 1 997) nomeia a exclusão dos indivíduos da participação nas redes de sociabilidade e dos sistemas de proteção que "cobrem" um indivíduo dos riscos da existência. A escola transformase na fronteira da integração, porém não provê um passe que tire os alunos de sua situação de vulnerabilidade. 
organização da tarefa na aula é pensada em função desse rígido esquema disciplinar (exclusão de trabalhos em equipe ou grupo dentro da aula, porque relaxa a disciplina) e inclusive a exigência acadêmica é processada como um dispositivo a serviço da disciplina.

Os pais desses setores constroem um forte cerco ao redor das escolas com a finalidade de apontar sua eficácia reguladora, exercendo um poder de polícia com o qual se propõem a neutralizar qualquer mudança que altere o habitus que caracteriza o ambiente familiar. Colocam seu esforço na homologação do habitus familiar e escolar. Trata-se de famílias tradicionais que vivem mundos pensados como ordens orgânicas estruturadas ao redor do respeito às hierarquias, às tradiçôes e à reverência às linhagens familiares. Tais jovens estão permeados pelo orgulho do pertencimento a um setor social que legitima sua situação de privilégio nas tradições familiares. Advêm daí suas expectativas de futuro que coincidem com as trajetórias já marcadas. As carreiras universitárias as quais se propõem seguir estão associadas a desempenhos profissionais tradicionais e registram-se poucos apetites para construção de uma vida diferente.

A mesma inibição para a construção de opções individuais está presente em jovens que provêm de setores médios que freqüentam escolas religiosas. Neste caso, as famílias apresentam-se como organizaçôes mais horizontais que as anteriores, nas quais se resgata o valor do afeto e do amor como elemento de coesão em um grupo familiar que gera uma densa presença na consciência dos filhos, naturalizando mandatos e neutralizando a imaginação alternativa. A família aparece como a referência obrigatória em cada definição e parece ser a única legitimada para justificar a ação. Nesses meninos há mais presença do bairro - o qual atua como um espaço de controle e de regulação - que nos anteriores. Diríamos que bairro, família e escola constroem uma fronteira dentro da qual se definem as opçôes para os jovens.

As instituições freqüentadas por esses jovens têm uma organização homologável para seu grupo familiar. A autoridade é definida como uma presença amigável e próxima, sempre disposta ao diálogo e à compreensão. São os laços interpessoais, as obrigações afetivas e a compreensão da funcionalidade das regras que sustentam o marco disciplinar. Há muito trabalho pastoral e um controle das consciências e, com elas, o da imaginação que, para o grosso desses meninos, deixa opçôes alternativas às marcadas pelo ambiente familiar e escolar fora do campo do pensável.

Em ambos os subgrupos, a busca da gratificação pessoal não aparece como a motivação central da ação e, embora seja certo que o resgate dos interesses e dos gostos dos meninos está presente no discurso dos pais, este parece antes fazer parte das concessóes necessárias para obter um ajuste funcional das condutas dos jovens - como se houvesse um reconhecimento de que os tempos 
mudaram e se tem que conceder algo para que os filhos sigam o caminho adequado.

É claro que estamos descrevendo ambientes e condicionantes de conduta cuja eficácia deveria ser constatada com estudos do prosseguimento das trajetórias desses jovens. E, ainda que seja certo que, para além dos esforços familiares e escolares, a reconfiguração individualista da ordem social colocará esses meninos em situação de se responsabilizar por suas ações e participar ativamente da construção de seu futuro, é possível ter como hipótese que suas escolhas terão uma clara ancoragem nas regulações familiares e escolares.

\section{A individualização como mandato}

No universo de jovens que constituem a amostra da pesquisa, da qual este texto em parte dá conta, distingue-se um grupo que parece estar inscrito claramente em um caminho de individualização entendido como ampliação de suas opções e, portanto, de suas margens de liberdade.

Trata-se de jovens provenientes de camadas médias esclarecidas, cujas trajetórias e posiçōes atuais têm relação com a constituição histórica das classes médias na Argentina e com a reversão da dinâmica de ascensão social que caracterizou nossa sociedade durante os primeiros 70 anos do século XX.

As classes médias, moldadas nos inícios do século XX por filhos de imigrantes, descolaram-se de sua situação de origem por meio de uma estratégia que combinava a obtenção de credenciais educacionais com a incorporação em um mercado de trabalho que se diferenciava e se ampliava como conseqüência da benéfica articulação do mercado nacional com o intercâmbio internacional.

A matriz igualitarista que caracterizou a Argentina até a década noventa do século passado decorreu de um singular processamento da concorrência social pelos recursos disponíveis. As aspirações por ascensão social tramitaram pela ampliação da oferta escolar por parte do Estado, que continha uma implícita promessa de promoção econômica e social.

Em um texto anterior (Tiramonti, 2004) sustentei que as estratégias que esses setores empregaram para procurar sua promoção lhes foram próprias e resultaram de uma identificação clara de quais eram os recursos que tinham a sua disposição para mobilizá-los na luta pela ascensão social. Portanto, longe de ser um estrato com pouca autonomia e atado à imitação de estratégias dos setores mais altos da população, constituíram-se por meio de estratégias que lhes foram próprias e moldaram um setor com capacidade de inovação e de uso dos recursos disponíveis.

Justifica-se essa digressão sobre as classes médias porque, de acordo com nossos dados, são novamente grupos pertencentes a essas camadas médias que 
- sobre a base de sua tradicional estratégia - inovam nos finais do século $\mathrm{XX}$, com o objetivo de neutralizar as tendências ao descenso social e manter-se em suas posições ou ganhar no processo de reestruturação que viveu o país nos últimos anos.

Os jovens pertencentes a esse grupo provêm de um ambiente familiar que já esteve submetido às exigências da individualização. Seus pais estão associados às atividades mais dinâmicas da economia e navegaram com êxito na transformação dos noventa, seja porque se encontravam em um posto de trabalho adequado ou porque puderam fazer uma leitura inteligente da situação, o que lhes permitiu mobilizar-se de acordo com as exigências do momento. Foram, em definitivo, flexíveis e competiram pelos lugares estratégicos do mercado. De modo que são grupos que inovaram no fragor da mudança e valorizaram a capacidade de mover-se, flexibilizar-se e aproveitar as oportunidades.

São grupos educados que consideram o conhecimento e o saber como recursos estratégicos para se posicionarem no mercado e escolhem escolas que priorizam a excelência acadêmica. Nesse caso, diferentemente do grupo de elite anteriormente analisado, o saber é valorizado como fonte de gratificação pessoal tanto pelos alunos como por seus professores e pais. Aqueles que sabem são admirados e respeitados, e este é o recurso pelo qual se legitima a autoridade. A proposta dessas instituições inclui seminários e matérias não convencionais que abarcam diferentes dimensões da cultura e da arte.

Ao mesmo tempo, há por parte de pais e docentes uma aposta forte na criatividade dos jovens e em sua capacidade de articular de modo original os recursos que lhes são proporcionados. É como se dissessem: aqui estão os recursos que nós lhes provemos para uma viagem futura cujo caminho e roteiro desconhecemos, porém cremos que isto é o que lhes será útil. Depende de vocês combiná-los e atualizá-los de forma que se transformem em um capital útil para se realizarem na vida.

A realização pessoal e o desenvolvimento de uma atividade gratificante, que permita um contínuo crescimento e atualização das potencialidades individuais, transformaram-se em uma exigência para esses jovens que não só precisam fazer sua leitura da realidade e decidir como se instalar nela, mas, além disso, são obrigados a fazer uma escolha que lhes garanta uma vida plena de desenvolvimento pessoal.

$\mathrm{Na}$ ideação do futuro, esses meninos constroem alternativas nas quais tentam aliar a gratificação pessoal a uma análise da viabilidade que o mercado dá para determinadas ocupaçôes. Constroem novos sentidos para as carreiras tradicionais e combinações de saberes e ocupações que lhes permitam articular-se funcionalmente num mercado que se reestrutura e gera novos nichos ocupacionais. 
Os ambientes familiares desses jovens estão organizados horizontalmente, porém sua estrutura e sua presença na vida dos meninos, em suas referências e suas opções, parecem ser menos densas que no restante dos grupos analisados anteriormente. A construção de projetos individuais que se contêm e se afagam a partir do grupo familiar parece ser a regra. Há presença de um discurso $p s i$ nos modos de pensar a família e a relação com os jovens, que é característico deste setor social na Argentina.

As escolas freqüentadas por esses meninos organizam-se ao redor desse permanente estímulo à esponsabilidade pessoal, ao autocontrole e à gratificação pelo trabalho escolar. Há um regime disciplinar que se baseia nessa construção individual da responsabilidade para sustentar uma ordem satisfatória para a convivência e o desenvolvimento das atividades escolares. A autoridade é uma presença próxima, solícita e atenta às necessidades intelectuais e afetivas dos alunos. Nada escapa ao olhar de diretores e responsáveis, tudo é processado a partir da conversação e da reflexão. Não há estado de ânimo, de conflito ou de problema que possa ser subtraído da atenção compreensiva dos agentes escolares. Sem dúvida, não se trata de um ambiente familiar nem de relações sustentadas nos afetos interpessoais; pelo contrário, há certa observância das normas e das regras do jogo e as relações com os alunos estão marcadas por uma distância intelectual que lhes outorga uma conotação específica e as diferencia das familiares.

Em síntese, é um grupo que constrói seu futuro em uma permanente busca de uma realização pessoal plena das gratificações que resultam de ocupações interessantes, inovadoras e capazes de proporcionar um significado atraente à existência.

\section{A competição como condição da concretização do projeto próprio}

Competir parece ser a motivação para a ação de um grupo de jovens que provêm de setores altos e médios da sociedade. Nesses casos, a auto-realização passa pela capacidade de estar sempre em carreira e pela gratificação por demonstrar-se e demonstrar uma permanente disposição à superação.

São jovens que se pensam líderes ou personalidades que sobressaem e são destinadas a conduzir outras vontades. Incluem-se nessa categoria jovens que transitam por circuitos socioculturais muito diferentes e que, portanto, concebem-se liderando mundos que têm pouco a ver entre si. Os critérios que definem o êxito ou o fracasso em cada um desses mundos são diferentes ou estão associados a atributos e a valores muito díspares.

Para alguns, trata-se de competir em um mundo globalizado no qual é possível deslocar-se sem obstáculos para obter uma formação de acordo com 
suas aspirações ou para se divertir, passear ou visitar amigos. Trata-se de um mundo fundamentalmente masculino, no qual os homens competem pelo êxito nos negócios, desempenham funções de liderança nas empresas, têm famílias formosas e vivem em casas dignas de ser registradas nas revistas que exibem os ricos e os exitosos.

Idealizam um mundo semelhante ao qual vivem ou, poder-se-ia dizer, preparam-se para ser exitosos nele. Não se trata, então, de jovens que se dispõem a cruzar a fronteira de seu habitat, não se trata de se pensar como fazedores de um futuro próprio que modifique seu ambiente, não há saltos, apenas uma opção de tomar a seu encargo os riscos de uma competição que lhes permita se manter no mesmo mundo, com os mesmos privilégios. Ganhar não um novo mundo, não seu próprio mundo, mas sua própria posição, atualizando as estratégias requeridas para isso, adequando-se às novas exigências e competindo sempre pelas mesmas posições.

Estes meninos freqüentam instituiçóes que ocupam todo seu tempo e que atuam como marco de controle e seleção de amizades e atividades recreativas. São instituições bilíngües que se propõem a formar sujeitos cosmopolitas e competitivos; que contam com uma organização pedagógica e institucional que favorece a aprendizagem do valor do esforço, da exigência e da competição. (Ziegler, 2004).

Há outros jovens fortemente motivados para a competição que se pensam líderes intelectuais, sociais ou políticos. Freqüentam escolas públicas, superexigentes, nas quais ingressam depois de haverem passado por uma rigorosa seleção. Acham-se depositários de uma tradição de líderes ilustrados e organizam sua vida em torno de uma permanente competição intelectual. Há uma pedagogia fundada na excelência e uma valorização do saber como fonte legitimadora das posições de privilégio.

Diferentemente dos anteriores, são jovens que transitam por espaços socioculturais heterogêneos que lhes proporcionam experiências, contatos e recursos com os quais alimentam suas fantasias de futuro. Esses jovens pensam-se exitosos na construção de um mundo que lhes será próprio e que, muitas vezes, é diferente do de seus pais. Em alguns casos, são impulsionados por seus pais para iniciar-se no caminho da competição; em outros, são opções pessoais que rompem com inércias e hábitos de origem.

Estes últimos são meninos e meninas que apostam na competência intelectual como um modo de romper o cerco das determinações familiares. Nesses casos, sentem-se verdadeiros artífices de seu futuro e sofrem como desgarramento a distância que constroem em relação a sua família de origem.

As escolas que freqüentam interpelam-nos permanentemente em sua condição de sujeitos da competição intelectual, constroem para eles um ambiente 
institucional que lhes demanda permanentemente superar-se e demonstrar que se pode mais; é quase como um treinamento para uma competição que se travará no futuro que não está definido, porém no qual terão que forjar para si uma posição destacada.

Em todo este grupo, a busca da vida boa está muito presente, embora não seja a motivação mais forte para a ação; de fato, são jovens que valorizam o esforço que a competição exige, sacrificam horas com os amigos e postergam outras atividades em favor de manter-se na carreira dos que se sobressaem.

As tecnologias de governo que essas instituições desenvolvem estão centradas na construção dessas subjetividades competitivas que se auto-regulam por meio de um permanente apelo para atualizar suas capacidades.

Em síntese, embora todos os jovens sejam atravessados pelos processos de individualização e pela exigência de ser eles mesmos, cada um deles aborda essa experiência a partir de condicionamentos sociais, familiares e escolares diferentes, que lhes provêm recursos, inibições, habilitações, expectativas e medos que se fazem presentes nos modos de abordar a construção de seu futuro.

\section{Os mandatos sociais sobre a escola}

Para além das expectativas que as famílias dos indivíduos ou os setores sociais desenvolvem em torno da escolarização, a sociedade constrói, para suas instituiçôes, mandatos que perpassam os desejos ou as expectativas particulares.

As instituições constituem-se como tais em torno de uma série de exigências e demandas que provêm do campo político, social ou econômico e que se articulam e combinam com as oportunidades e possibilidades que um determinado momento histórico proporciona. A condição das instituições e a definição de suas funçôes e conteúdos estão atravessadas pelas lutas e conflitos de poder. É na entronização das instituições e na construção de sua função na sociedade que se dirimem posiçôes e se estabelecem, em muitos casos, a linha divisória entre ganhadores e perdedores.

A construção da estrutura institucional da modernidade esteve atravessada por uma série de processos de ida e de volta nos quais se enfrentavam propostas e estas se resolviam a favor de uma ou de outra. Jaques Donzelot (1998), por exemplo, explica, em seu texto La policía de las famílias, a complexa trama de demandas políticas e sociais que confluíram na conformação da família moderna. Da mesma forma, a escola da modernidade foi uma lenta construção na qual convergiram exigências provenientes do campo da política e as necessidades de governabilidade de uma sociedade que se pretendia despojar-se das regulações medievais, devido a demandas do campo da produção favoráveis ao disciplinamento da mão-de-obra. Também estão presentes as lutas dos setores 
populares e as demandas por educação das organizações sociais (Suriano, 2001; Barranco, 1990).

Nos primórdios do século XX, na Argentina, o mandato para a escola fundamental esteve claramente ancorado na construção de um dispositivo de regulação em consonância com o governo de uma sociedade de homens livres; da mesma forma, a exigência para a escola média esteve relacionada à seleção e à construção da diferença. A afluência de uma massa de imigrantes nos finais do século XIX e as políticas de expansão colonialista dos países expulsores de população geraram em nosso país uma "questão" em torno da conformação da nacionalidade que produziu uma exigência para as escolas e seus agentes destinada a incentivar o fervor patriótico (Bertini, 2001). Na confluência desse mandato social que gerou instituições e as distribuiu ao largo e ao longo do país e as aspirações particulares de frações dos setores populares, construiu-se a possibilidade de ascensão social para um grupo da população.

O caráter universal desse mandato educacional articulou-se com o objetivo mais geral de modernização a partir de um agente central que era o Estado. Nesse caso, o projeto social associou-se funcionalmente às aspirações de um grupo social. Obviamente, esse movimento ascendente não incluiu todos, já que discriminou e segregou uma parte da população à qual a educação fechou o caminho da ascensão social. Para além da disponibilidade de uma oferta educacional e do interesse familiar de participar da ascensão, nem todos dispunham dos recursos materiais e simbólicos que lhes permitissem subir no trem do ascenso.

Do mesmo modo, nos anos 1960 construiu-se um discurso que articulou educação e desenvolvimento, que condicionou um alinhamento da produção do sistema aos requisitos do aparato produtivo e às exigências que este colocava em termos de recursos humanos. Desta perspectiva, os esforços coletivos e individuais em matéria educacional justificavam-se, de um lado, em razão de seu impacto no campo do desenvolvimento econômico e, de outro, pelos rendimentos pessoais.

Seja como for, ambos constituíram-se exigências para o sistema e critério de referência para a valorização das instituições escolares. Nesse caso, como no anterior, o mandato de articular escola e demanda de emprego questionou de modos diferentes os distintos grupos socioculturais devido a sua localização possível no mercado de trabalho. Assim, para alguns se tratava de formação técnica de nível secundário; para outros, de uma formação humanista que os direcionava a empregos do setor de serviços ou à formação superior; finalmente, estavam aqueles que se consideravam chamados a formar-se nas novas profissões de conteúdo tecnológico, como as engenharias.

No final do século XX e começo do XXI, os mandatos para as escolas são diferentes e constituem um conjunto heterogêneo que interpela pais, alunos e 
docentes em relação tanto ao papel que desempenham quanto ao lugar que ocupam dentro do concerto social.

\section{mandato da contenção}

Em primeiro lugar, quero fazer menção à tão comentada demanda de contenção das novas geraçôes. $\mathrm{O}$ mandato de conter atravessa todas as instituições escolares, mas, sem dúvida, são múltiplos os sentidos que a ele se atribuem. Assim, para os docentes de algumas das escolas que denominamos de elite, o conter está relacionado ao afeto e à compreensão que requerem os jovens que não encontram em suas famílias a atenção amorosa condizente com as necessidades de sua idade. Para outros docentes desse mesmo grupo socioeconômico, conter está mais relacionado a estabelecer um marco disciplinar que regule as condutas consoantes com uma formação tradicional; para os pais desses mesmos grupos, o conter tem outro sentido e está relacionado a mais tempo na escola e à oferta de outras atividades extracurriculares para seus filhos; ou, no segundo caso, à atenção de um adulto significativo que escute e oriente os jovens.

Do mesmo modo, para uma parte dos pais de classe média, sua demanda de contenção está relacionada a um trato agradável e afetuoso com seus filhos e a um ambiente adequado para o desenvolvimento das amizades juvenis. Tratase possivelmente de grupos familiares organizados horizontalmente, penetrados pela cultura $p s i$, que optaram por um modelo de regulação dos filhos centrado no autocontrole e na assunção individual das responsabilidades e dos riscos.

A pesquisa mostrou muitas assimetrias no processo de individualização dos jovens. Para um grupo dos setores médios e altos, está claro que há uma ampliação das opções individuais e uma maior presença de decisões autônomas. Dentro desses mesmos setores socioeconômicos há jovens cujas opções continuam fortemente influenciadas pelos pertencimentos de classe, pelo ambiente familiar ou pela própria instituição escolar. No extremo mais baixo da escala social, repete-se a ampliação de autonomia individual; contudo, neste caso, é difícil fazer uma associação com maiores graus de liberdade, pois estaríamos diante do que Castel (1997) chama individualização negativa, ou Robles (1999), individuação; noções com as quais se quer explicar a situação de uma parte da população que está compulsivamente submetida ao processo de ser "eles mesmos" (Sennett, 2000), sem recursos e sem rede de proteção social.

É nos setores mais baixos da população que esse mandato adquire uma significação com forte conteúdo reprodutor. Para muitos dos docentes que atendem a esses grupos sociais, a "contenção" passa por oferecer um espaço institucional de proteção social para aqueles que vivem em territórios caracteri- 
zados pela desintegração. Conter é proteger momentaneamente seus alunos da violência que caracteriza o meio social em que vivem. Nesse caso, a escola é pensada como um espaço de resistência ou como uma instituição que aproxima esses meninos de algo que se pareça com o mundo dos integrados. E, dentro desse grupo, distinguimos as instituiçōes religiosas cuja proposta tem um claro componente pastoral que contém uma promessa de "proteção tutelar" e mantém uma pretensão civilizatória, diferente daquelas outras que se propõem a oferecer uma assistência material e pedagógica e um âmbito de "compreensão" e de "convivência entre pares" para aqueles que participam ativamente da cultura da margem (Tiramonti, 2004).

Da mesma forma, há um discurso, oriundo fundamentalmente dos âmbitos oficiais, que demanda essa função "de contenção" da escola, expressa na pretensão de universalização dos níveis médios de educação, e que vem unido tanto ao discurso que sublinha o valor do conhecimento na sociedade atual quanto a uma retórica que associa contenção escolar a controle do risco social e pensa a escolarização como um dispositivo de segurança urbana para tirar os jovens da rua e prevenir a potencialidade de delito por parte de um grupo social que não estuda nem trabalha. Embora a pesquisa tenha mostrado que a vida de delito desses jovens se mantém paralelamente a sua frequiência à escola ou ao trabalho (Duschatzky; Corea, 2000; Kessler; Luzzi, 2004), essa associação de escola e prevenção do delito está muito presente e constrói outra acepção para a exigência de contenção.

Cremos não forçar a interpretação, se sublinharmos que "o conter" denota uma percepção de falta ou de déficit de contenção, que a nosso ver se relaciona com a escassa presença de organizaçóes e instituições na estrutura social capazes de abrigar a existência dos jovens e remete ao processo de desinstitucionalização mais acima mencionado. Para além da valorização que os diferentes atores têm da escola, está claro que esta se transformou quase que na única instituição com capacidade de abrigar esse grupo etário. A escola constituiu-se o lugar para o estar dos jovens e isso a transforma institucionalmente em um espaço no qual o presente e os modos de habitá-lo adquirem uma relevância que não teve anteriormente.

\section{Das expectativas para o futuro à valorização do presente}

A escola é uma instituição pensada na intersecção de passado, presente e futuro. Sabe-se que é por meio dela (cada vez menos exclusivamente dela) que se transmite de geração a geração um acervo cultural, uma versão da história, uma valorização dos traços de identidade da nacionalidade, uma cosmovisão que reconhece tradiçôes heróicas, que anula outras e que dá forma ao que 
Wallerstein (1996) chama a versão nacional do arbitrário cultural da civilização ocidental. Nessa invenção do passado, a escola aponta a construção das representações que os argentinos temos de nós mesmos, de nossos vizinhos, de nossos direitos, do lugar que ocupamos no mundo, do que deveríamos ocupar. É deste lugar que se entende o presente e se constrói uma hipótese sobre o futuro possível.

A mediatização da cultura deslocou a escola do lugar exclusivo de portador da versão oficial de nossa história e, com isso, de nossa identidade e destino. É possível que os textos televisivos façam hoje um aporte mais substancioso que a escola para as construções de identidade e que nestes a relação com o passado seja mais efêmera e menos importante como fundadora do presente. Com isso, queremos dizer que o relato escolar se sustenta em uma seqüência temporal em que o passado é fundante do presente, explica-o e o faz inteligível. Em troca, o discurso televisivo justifica-se como um mero presente.

Por outra parte, e sempre considerando essa seqüência entre passado, presente e futuro, o relato escolar estabeleceu um sentido teleológico entre passado, presente e futuro. Tanto na construção das trajetórias coletivas, de povos, de nações ou de etnias, quanto nos destinos individuais, está presente esta idéia moderna de que existia uma seqüência lógica e racional entre as opçóes do passado, as situaçôes presentes e os destinos futuros. Todo o desenvolvimento intelectual do século XX esteve ancorado nesta visão dos caminhos do progresso, no qual o presente se dilui e se legitima por suas raízes no passado e por suas promessas para o futuro.

A escola é uma instituição tradicionalmente ancorada nessa seqüência temporal. O passado deve ser configurado, inventado, transmitido pela instituição para construir uma representação que torne inteligível o presente e justifique a pretensão do futuro. Ao mesmo tempo, a escola contém uma promessa de futuro. A promessa de integração e inclusão por meio da incorporação no mercado de trabalho e nos códigos das trocas sociais e da promessa de autonomia individual mediante o desenvolvimento das potencialidades que carregamos como indivíduos.

Assim como a modernidade modificou a percepção do tempo e do espaço, possibilitando primeiro a separação entre ambos, as mudanças acumuladas nos últimos quarenta anos transformaram essa percepção da modernidade (Ortiz, 1996). Vivemos uma cultura que, na seqüência temporal, privilegia o presente. Essa entronização do "hoje" ou do instante vai de mão dada com a perda da ilusão no progresso, o ceticismo sobre o futuro e o deslocamento da ética do trabalho em favor da estética do consumo. A demanda por gratificação, que se ancora no desejo e na busca de sua satisfação, deslocou, em grande medida, uma ética do sacrifício que deslocava a gratificação para o futuro (Bauman, 2000). 
Nossos dados de pesquisa são claros quanto à valorização da gratificação e da realização pessoal tanto para os pais como para os jovens dos diferentes estratos das classes médias. Este fato gera para as escolas uma demanda que antes não estava presente ou, pelo menos, não tinha a relevância com a qual se apresenta hoje.

Os pais avaliam não só, nem principalmente, a construção do futuro que a escola promete, mas que presente ela oferece a seus filhos; e, dessa forma, podem-se mudar os filhos de escola em função de um presente avaliado como insatisfatório:

Luciana fez a escola no Colégio XXX que, como todos sabemos, tem muito prestigio. Ela era brilhante na escola. Eu não tenho nada a dizer quanto à formaçāo intelectual que essa escola oferece, porém, não existe cuidado nem contenção para os meninos. Leandro começou ali, mas logo o mudei. Como tive que fazer isso mais ou menos rápido, escolhemos uma escola privada, eu tinha prejuizo com a escola privada, porém, escolhemos uma que é exigente, mas que, além disso, mantém um contato permanente dos dirigentes com os meninos, cuidam deles e eles não se sentem pressionados, fundamentalmente estão contentes na escola.

Todas as variantes da contenção que explicitamos no ponto anterior confluem na construção de uma demanda por um presente gratificante. Tal demanda exige das escolas gerar propostas extracurriculares, dar aos alunos afeto, protegêlos do meio social no qual vivem, evitar o delito, o que torna obrigatório repensar a gramática escolar para reconfigurar a equação do tempo no espaço escolar.

\section{Referências bibliográficas}

ARTEGA BOTTELLO, N; LARA CARMONA, V. Violencia y distancia social: una revisión. Papeles de Población. CIEAP-UAEM, n.40, 2004.

BARBERO, José Martín. La educación desde la comunicación. Buenos Aires: Norma, 2002.

BARRANCO, Dora. Anarquismo, educación y costumbres en la Argentina de fin de siglo. Buenos Aires: Contrapunto, 1990.

BAUMAN, Zygmunt. Trabajo, consumismo y nuevos pobres. Espanha: Gedisa, 1999. . La Modernidad líquida. Buenos Aires: Fondo de Cultura Económica, 2000.

BECK, Ulrich. Teoría de la sociedad del riesgo. In: BERIAIN, Josetxo (Comp.). Las consecuencias perversas de la modernidad. Modernidad contingencia y riesgo. Madrid: Amorrortu, 1997. . Hijos de la libertad. Buenos Aires: Fondo de Cultura Económica, 1999. . La democracia y sus enemigos. Buenos Aires: Paidos, 2000. 
BERTONI, A. Patriotas, cosmopolitas y nacionalistas: la escuela y la formación de la nacionalidad (1884-1890). Buenos Aires: Fondo de Cultura Económica, 2001.

BUCKINGHAM, David. Crecer en la era de los medios electrónicos, tras la muerte de la infancia. Madrid: Fundación Paideia, Morata, 2002.

CASTEL, Robert. La metamorfosis de la cuestión social. Paidos, Buenos Aires, 1997.

CASTELLS, Manuel. La era de la información. Madrid: Alianza Editorial, 1998.

DELEUZE, Gilles. Posdata de la sociedad del control. In: FERRER, Cristian (Comp.). Lenguaje libertario: filosofía de la protesta humana. Montevideo: Nordan - Comunidad, 1991.

DONZELOT, Jaques. La policía de las familias. Valencia: Pre-textos, 1998.

DUBET, F; MARTUCCELLI, D. En la escuela: sociología de la experiencia escolar. Espanha: Losada, 1998.

DUSCHATZKY, Silvia. La escuela como frontera: reflexiones sobre la experiencia escolar de jóvenes de sectores populares. Buenos Aires: Paidos, 1999.

DUSCHATZKY, Silvia; COREA, Cristina. Chicos en banda. Los caminos de la subjetividad en el declive de las instituciones. Buenos Aires: Paidos, 2002.

ELIAS, Norbert. La sociedad de los individuos. Barcelona: Península, 1990.

FOUCAULT, Michel. Vigilar y castigar: Nacimiento de la prisión. México: Siglo XXI. 1996.

GIDDENS, Anthony. Modernidad e identidad del yo. Barcelona: Península, 1995. . Un mundo desbocado. México: Taurus, 2000.

GORZ, André, Metamorfosis del trabajo: búsqueda del sentido. Madrid: Sistema, 1991.

KESSLER, Gabriel, Redefinición de las identidades sociales en tiempos de cambio. Una tipología para la experiencia del empobrecimiento. In: SVAMPA, Maristella. Desde abajo. Buenos Aires: Biblos, 2000.

KESSLER, Gabriel; LUZZI, Mariana. Sociología del delito amateur. Buenos Aires: Paidos, 2004.

LIPOVESKY, Gilles. El crepúsculo del deber. Barcelona: Anagrama, 2000.

LUHMANN, Niklas e DE GEORGI, Raffaele. Teoría de la sociedad. México: Triana Editores, 1998.

MONTES, Nancy. Adolescentes y jóvenes en contexto. El marco cercano: la familia y el marco amplio: los otros. In: TIRAMONTI, G. (Comp.). La trama de la desigualdad educativa: mutaciones recientes en la escuela media. Buenos Aires: Manantiales, 2004.

ORTIZ, Renato. Otro territorio. Ensayos sobre el mundo contemporáneo. Buenos Aires: UNQ, 1996.

PARKING, Frank. El cierre social como exclusión. In: PARKING, Frank. Marxismo y teoría de clases: una critica burguesa. Buenos Aires: Espasa Calpe, 1964. 
POLIAK, Nadina. Reconfiguraciones recientes en la escuela media: escuela y profesores en una geografía fragmentada. In: TIRAMONTI, Guillermina (Comp.) La trama de la desigualdad educativa. Mutaciones recientes de la escuela media. Buenos Aires: Manantial, 2004.

QUEVEDO, L. A. La escuela frente a los jóvenes, los medios de comunicación y los consumos culturales en el siglo XXI. In: TENTI, E. Educación Media para todos. Buenos Aires: IIPE/ Altamira/OSDE, 2003.

ROBLES, Fernando. Los sujetos y la cotidianeidad. Elementos para una microsociología de lo contemporáneo. Concepción, Chile: Sociedad Hoy, 1999.

SENNETT, Richard. La corrosión del carácter: las consecuencias personales del trabajo en el nuevo capitalismo. Barcelona: Anagrama, 2000.

SURIANO, Juan. Anarquistas, cultura y políticas literarias en Buenos Aires 1890-1910. Buenos Aires: Manantial, 2001.

TEDESCO, Juan Carlos. Educación y ciudadanía en el nuevo capitalismo: algunas notas e hipótesis de trabajo. Revista Propuesta Educativa. Buenos Aires: Novedades Educativas, FLACSO, n. 26, 2003.

TIRAMONTI, Guillermina (Comp.). La trama de la desigualdad educativa. Mutaciones recientes de la escuela media. Buenos Aires: Manantial, 2004.

TIRAMONTI, Guillermina. La fragmentación educativa y los cambios en los factores de estratificación. In: TIRAMONTI, G. (Comp.). La trama de la desigualdad educativa: mutaciones recientes en la escuela media. Buenos Aires: Manantiales, 2004.

TORRADO, Susana. Historia de la familia en la Argentina moderna (1870-2000). Buenos Aires: Ediciones de la Flor, 2003.

VICENT, G.; LAHIR, B.; THIN D. Sobre a história e a teoria da forma escolar. Revista Educação, n.33. Universidade Federal de Minas Gerais, Belo Horizonte, 2001.

WALLERSTEIN, I. Después del liberalismo. Madrid: Siglo XXI, 1996.

ZIEGLER, Sandra. La escolarización de las elites: un acercamiento a la socialización de los jóvenes de sectores favorecidos en la Argentina actual. In: TIRAMONTI, G. (Comp.). La trama de la desigualdad educativa: mutaciones recientes en la escuela media. Buenos Aires: Manantiales, 2004.

Recebido em 28 de março de 2008 e aprovado em 13 de junho de 2008. 